\title{
Stereotactic body radiotherapy for centrally-located lung tumors with 56 Gy in seven fractions: A retrospective study
}

\author{
SHURI AOKI $^{1}$, HIDEOMI YAMASHITA ${ }^{1}$, AKIHIRO HAGA ${ }^{2}$, TAKESHI OTA ${ }^{1}$, WATARU TAKAHASHI ${ }^{1}$, \\ SHO OZAKI ${ }^{1}$, KANABU NAWA ${ }^{1}$, TOSHIKAZU IMAE ${ }^{1}$, OSAMU ABE $^{1}$ and KEIICHI NAKAGAWA ${ }^{1}$ \\ ${ }^{1}$ Department of Radiology, University of Tokyo Hospital, Tokyo 113-8655; \\ ${ }^{2}$ Medical and Dentistry Laboratory, University of Tokushima, Tokushima 770-8501, Japan
}

Received February 3, 2018; Accepted July 3, 2018

DOI: $10.3892 / \mathrm{ol} .2018 .9188$

\begin{abstract}
Stereotactic body radiotherapy (SBRT) for centrally-located lung tumors remains a challenge because of the increased risk of treatment-related adverse events (AEs), and uncertainty around prescribing the optimal dose. The present study reported the results of central tumor SBRT with 56 Gy in 7 fractions (fr) at the University of Tokyo Hospital. A total of 35 cases that underwent SBRT with or without volumetric-modulated arc therapy consisting of $56 \mathrm{~Gy} / 7 \mathrm{fr}$ for central lung lesions between 2010 and 2016 at the University of Tokyo Hospital were reveiwed. A central lesion was defined as a tumor within $2 \mathrm{~cm}$ of the proximal bronchial tree (RTOG 0236 definition) or within $2 \mathrm{~cm}$ in all directions of any critical mediastinal structure. Local control (LC), overall survival (OS), and AEs were investigated. The Kaplan-Meier method was used to estimate LC and OS. AEs were scored per the Common Terminology Criteria for Adverse Events Version 4.0. Thirty-five patients with 36 central lung lesions were included. Fifteen lesions were primary non-small cell lung cancer (NSCLC), 13 were recurrences of NSCLC, and 8 had oligo-recurrences from other primaries. Median tumor diameter was $29 \mathrm{~mm}$. Eighteen patients had had prior surgery. At a median follow-up of 13.1 months for all patients and 18.3 months in surviving patients, 22 patients had died,
\end{abstract}

Correspondence to: Dr Hideomi Yamashita or Dr Shuri Aoki, Department of Radiology, University of Tokyo Hospital, 3-7-1 Hongo, Bunkyo-ku, Tokyo 113-8655, Japan

E-mail: yamachan07291973@yahoo.co.jp

E-mail: daisyshuri@yahoo.co.jp

Abbreviations: $\mathrm{BED}_{10}$, biologically effective dose $\alpha / \beta=10 \mathrm{~Gy}$; fr, fraction; LC, local control; LCR, local control rate; NSCLC, non-small cell lung cancer; OAR, organ at risk; OS, overall survival; PFS, progression-free survival; SBRT, stereotactic body radiation therapy; VATS, video-assisted thoracoscopic surgery; VMAT, volumetric modulated arc therapy

Key words: central lung tumor, stereotactic body radiotherapy, volumetric modulated arc therapy, lung cancer, radiation pneumonitis, pulmonary oligo-recurrence ten due to primary disease (4 NSCLC), while three were treatment-related. The 1- and 2-year OS were 57.3 and $40.4 \%$, respectively, and median OS was 15.7 months. Local recurrence occurred in only two lesions. 1- and 2-year LC rates were both $96 \%$. Nine patients experienced grade $\geq 3$ toxicity, representing $26 \%$ of the cohort. Two of these were grade 5 , one pneumonitis and one hemoptysis. Considering the background of the subject, tumor control of our central SBRT is promising, especially in primary NSCLC. However, the safety of SBRT to central lung cancer remains controversial.

\section{Introduction}

Surgical excision is the gold standard therapy for early-stage non-small cell lung cancer (NSCLC), However, the increasing number of elderly patients with comorbidities demonstrates the need for less-invasive therapies (1).

Stereotactic body radiotherapy (SBRT) for peripheral lung tumors has emerged as a safe and noninvasive alternative to surgical resection with equivalent rates of local tumor control, and has been established as a standard of care in patients with inoperable lung tumors oad in those declining surgery (2-4). Recently, the role of SBRT in oligo-recurrence and sync-oligometastases in the lung parenchyma has also come under investigation, with promising results (5-9).

However, for both surgery and SBRT, established adaptation is limited to peripheral lesions. Surgical resection of central tumors requires a larger resection area than peripheral lesions, and carries a high risk of complications (10-12). Likewise, central SBRT remains a challenge, because the central thoracic structures are considered to have multiple organs at risk (OARs), increasing the risk of adverse events (AEs). Timmerman et al reported in 2006 that SBRT of central tumors carried an increased risk of severe toxicity, up to 11 times higher that of peripheral tumors (13). Although multiple centers have reported various dose divisions in the search for a safe and effective regimen, it is unknown whether SBRT can be applied to all centrally located tumors or whether there are locations which are too close to OARs.

In our hospital, SBRT for central lung lesions is actively performed as an alternative to surgery when the patient is not a good surgical candidate or surgery is declined. Since 2011, we have treated central lung tumors with a $56 \mathrm{~Gy} / 7 \mathrm{fr}$ prescription 
[Biological effective dose $\left(\mathrm{BED}_{10}\right)=100.8 \mathrm{~Gy}$ ]. The primary purpose of this study was to assess the toxicity of SBRT with $56 \mathrm{~Gy} / 7 \mathrm{fr}$ in central lesions, and to evaluate the validity of this treatment in our institution.

\section{Materials and methods}

Patients and materials. From October 2011 to October 2016, 35 patients with 36 central lesions, either NSCLC or pulmonary/mediastinal oligo-recurrence, were treated with stereotactic body radiation therapy (SBRT) with or without volumetric modulated arc therapy (VMAT) at the University of Tokyo Hospital. All patients provided written informed consent, Data from the electronic medical record were retrospectively analyzed.

We excluded tumors located at or involving the hilar structures and those invading the bronchial tree or mediastinum, which are not considered safe targets for central SBRT regimens (14), as well as those that required additional fractions, such as 50 Gy in 10 fractions (fr). We also excluded cases of obvious idiopathic pulmonary fibrosis on computed tomography (CT). We defined a central lesion as a tumor within $2 \mathrm{~cm}$ of the proximal bronchial tree, as described in RTOG $0236(15,16)$, or within $2 \mathrm{~cm}$ in any directions of any critical mediastinal structure, including the bronchial tree, esophagus, heart, brachial plexus, major vessels, spinal cord, phrenic nerve, and recurrent laryngeal nerve $(5,17,18)$.

Treatment planning. Patients were immobilized in a stereotactic body frame and underwent a four-dimensional (4D) CT scan (2 mm sections). Scans were performed using an external respiratory monitoring system (AZ-733 $\mathrm{V}^{\circledR}$; Anzai Medical, Tokyo, Japan) with free breathing or with abdominal compression in cases where tumor excursion exceeded $1 \mathrm{~cm}$. In our institution, 4D-CT for planning divides the respiratory cycle into 10 sections. Respiratory phase data were transferred to a treatment planning system (TPS) (Pinnacle ${ }^{3 \circledast}$, version 9.10; Philips, Best, The Netherlands). Gross tumor volume (GTV) was delineated in each respiratory phase using the lung window (window, 1,600 HU; level, -300 HU). These $10 \mathrm{GTVs}$ were fused to form the internal target volume (ITV). A uniform $5 \mathrm{~mm}$ margin was then added to create the planning target volume (PTV) (19). For the main OARs (heart, lungs, esophagus, spinal cord, proximal tracheobronchial tree, and brachial plexus) were contoured consistent with guidelines provided by Radiation Therapy Oncology Group Trial (RTOG) $0236(15,16)$.

Treatment procedure and dose. Patients treated between October 2011 and March 2013 received a conventional SBRT plan using 6-11 beams. Patients treated between April 2013 and October 2016 received volumetric modulated arc therapy (VMAT-SBRT) with 6 or 10 MV beams. VMAT plans were designed using a single partial arc with angle ranges of $-40^{\circ}$ to $180^{\circ}$ (left lung) or $-180^{\circ}$ to $40^{\circ}$ (right lung), which has been previously described in detail $(19,20)$. Thirty-five patients received 56 Gy in $7 \mathrm{fr}$ to cover $95 \%$ of the PTV $\left(\mathrm{D}_{95 \%}\right)$. This dose was set in 2011 with the intention of increasing the number of fractions above that for peripheral lesions $(48 \mathrm{~Gy} / 4 \mathrm{Fr}$ ) while maintaining BED >100 Gy (21). Doses to OARs were required to meet explicit objectives as follows: V20 $<10 \%$ (less than $10 \%$ of the volume receiving $20 \mathrm{~Gy}$ ) and V5 $<25 \%$ for the ipsilateral lung, V20 $=0 \%$ and V5 $<15 \%$ for the contralateral lung, V15 $=0 \%$ for spinal cord, V30 $=0 \%$ for heart and liver, and V50 $=0 \%$ for body $(15,20,22)$. Treatment planning was performed using a3D RTP (Pinnacle ${ }^{3}$, New Version 7.4i; Philips). The collapsed cone convolution method together with the superposition algorithm were used for heterogeneity correction for the lungs. All final calculations were performed with a grid size of $2.0 \mathrm{~mm}$. Dose distributions were calculated using peak exhalation CT data.

Planning target coverage aimed to cover the PTV with 95\% of the prescribed dose. The main OARs were healthy lung, spinal cord, heart, and esophagus. Treatment plans were required to meet explicit objectives as follows: V20 $<10 \%$ (less than $10 \%$ of the volume receiving $20 \mathrm{~Gy}$ ) and V $5<25 \%$ for the ipsilateral lung, V $20<0 \%$ and V5 $<15 \%$ for the contralateral lung, V15 $=0 \%$ for spinal cord, V30 $=0 \%$ for heart and liver, and $\mathrm{V} 50=0 \%$ for body (23).

Follow-up/chart review. Follow-up consisted of a history and physical examination and non-contrast chest CT scan, beginning 2 months after SBRT, then every 3 months for 2 years, and at least every 6 months thereafter. In cases of suspected tumor relapse or progression, a contrast-enhanced CT scan or a ${ }^{18} \mathrm{~F}$-fluorodeoxyglucose positron emission tomography/CT (FDG-PET/CT) was performed. Local recurrence was defined as progressive and increasing $\mathrm{CT}$ scan abnormalities which were confirmed by progressive and incremental increases in the maximum standardized uptake value (SUVmax) of a lesion on serial PET imaging, with or without biopsy. The SUVmax was calculated as the most intense voxel within the volume of interest. All controversial cases were discussed at a tumor board and either verified by biopsy or by consensus.

All hospital records, follow-up notes, and imaging data were reviewed. Acute and late AEs were assessed according to the Common Terminology Criteria for Adverse Events Version 4.0 (CTCAE v 4.0). Dosimetric quality of treatments was measured from dose volume histogram (DVH) analysis. Doses to OARs were calculated for the following structures: Point dose maximum to the proximal tracheobronchial tree (proximal tracheobronchial tree point), maximum dose received by $5 \mathrm{cc}$ of the proximal tracheobronchial tree (proximal tracheobronchial tree $5 \mathrm{cc}$ ), mean total lung dose (MLD total), volume of lung receiving 5/10/20 Gy or more (V5/V10/V20), and maximum dose to spinal cord/esophagus/heart/brachial plexus.

Statistical analysis. Descriptive statistics for categorical variables are reported as frequency and percentage, whereas continuous variables are reported as median (range). For categorical variables, comparisons between groups were made using Pearson's $\chi^{2}$ tests. The 1-year local control rate (LCR), overall survival (OS), and relapse-free survival (RFS) were defined over the period from the first day of SBRT until death, recurrence, or last patient contact, and were calculated using Kaplan-Meier curves. The statistical analyses were performed using R software (https://www.r-project. org/), and significance of univariate analyses was set at $\mathrm{P}<0.05$. 
Table I. Patient and treatment characteristics.

\begin{tabular}{ll}
\hline Patient characteristics & No. $(\%)$ \\
\hline
\end{tabular}

Age, years
$\geq 75$
$<75$
Sex
Male
Female
KPS, \%
$\geq 90$
$<90$

Surgical history

Yes

No

17 (49)

$18(51)$

$25(71)$

$10(29)$

27 (77)

8 (23)

Chest RT history

Yes

No

COPD

Yes

No

KL-6, U/ml

$>500$

$\leq 500$

No data

Smoking history

Current

Past only

Never

$18(51)$

17 (49)

2 (6)

33 (94)

Cancer type $^{\mathrm{a}}$

Primary NSCLC

Recurrent NSCLC

Recurrent non-NSCLC

11 (31)

24 (69)

2 (6)

27 (77)

6 (17)

9 (26)

14 (40)

12 (34)

15 (28)

13 (36)

8 (16)

Definition of 'Central'

RTOG 0236 definition

$20(56)$

Others

16 (44)

Tumor diameter, cm

$\geq 3$

$<3$

$18(50)$

$18(50)$

In total, 36 tumor samples were analyzed from 36 patients. RTOG 0236 definition $(15,16)$. KPS, Karnofsy performance scale; RT, radiotherapy; COPD, chronic obstructive pulmonary disease; KL-6, Sialylated carbohydrate antigen Krebs von den Lungen-6; NSCLC, non-small cell lung cancer; Sq, squamous cell carcinoma; RTOG 0236, radiation therapy oncology group trial 0236.

\section{Results}

Patient and treatment characteristics. A total of 35 patients with 36 lesions were evaluated. All cases were treated with $56 \mathrm{~Gy}$ in $7 \mathrm{fr}\left(\mathrm{BED}_{10}=100.8 \mathrm{~Gy}\right)$. Patients and treatment characteristics are listed in Table I. The median age of patients
Table II. SBRT treatment characteristics and tumor volumes of 36 tumors.

\begin{tabular}{lc}
\hline Characteristics & Median (range) \\
\hline Tumor diameter, cm & $29(11-70)$ \\
PTV, cm ${ }^{3}$ & $60.13(7.2-388.8)$ \\
ITV, cm ${ }^{3}$ & $21.16(0.99-217.2)$ \\
Lung dose & $29.61(16.4-63.7)$ \\
V5, \% & $18.9(7.02-43.9)$ \\
V10, $\%$ & $11.31(2.1-17.91)$ \\
V20, \% & $679.9(299.6-1256.5)$ \\
MLD, cGy & $548.6(20.0-5736.1)$ \\
Trachea & $135.7(30.2-2563.8)$ \\
Max dose (point), cGy & \\
Max dose (5cc), cGy & $5,090.9(142.0-9527.9)$ \\
Carina & $1,145.7(1206-2366.8)$ \\
Max dose (point), cGy & \\
Max dose (5cc), cGy & $1,699.8(463.2-6551.2)$ \\
Esophagus & $1,296.5(101-2335.7)$ \\
Max dose (point), cGy & \\
Max dose (5cc), cGy & $1.715(0-24.42)$ \\
Heart & $5,618.9(40.3-6505.1)$ \\
V30, \% & \\
Max dose (point), cGy & \\
Spine & \\
Max dose (point), cGy & \\
Chest wall & \\
Max dose (point), cGy & \\
\hline
\end{tabular}

SBRT, stereotactic body radiotherapy, PTV, planning treatment volume; ITV, internal target volume; V5 (10/20/30), Percentage of the volume of an organ receiving $5(10 / 20 / 30)$ Gy; MLD, mean lung dose.

was 74 years (range 45-89 years), and the median of Karnofsy performance scale (KPS) was 90\% (range 80-100). SBRT treatment characteristics and tumor volumes for the study population are summarized in Table II. Fifteen lesions were primary NSCLC, 13 were local recurrence or mediastinal lymph nodes involved in NSCLC, and 8 were non-NSCLC pulmonary oligo-recurrences. Eighteen of the 35 patients $(51 \%)$ had undergone surgery for the lung tumor before SBRT, $13(37 \%)$ of which were salvage cases for a postoperative pulmonary recurrence. We usually distinguish 'ultra-central' tumors directly abutting the central airway (14); most of these tumors were treated with a different protocol, namely $50 \mathrm{~Gy}$ in $10 \mathrm{fr}$, but in this analysis, four 'ultra-central' cases receiving 56 Gy in 7 fr were included.

LC and survival. The median follow-up period for all patients was 13.1 months (range, 4.5-64 months) and that for survivors was 18.3 months (range, 5.8-51 months). During follow-up, local recurrence occurred in only two lesions $(6 \%)$. The first was a case of pulmonary oligo-recurrence from esophageal 
Table III. Adverse events of patients.

Grade (CTCAE4.0), no. (\%)

\begin{tabular}{lccccc}
\cline { 3 - 5 } Adverse events & I & II & III & IV & V \\
\hline Acute & & & & & - \\
Esophagitis & $6(17)$ & $1(3)$ & - & - & - \\
Dermatitis & $2(6)$ & $3(9)$ & - & - & - \\
All & $8(23)$ & $4(12)$ & - & - & $1(3)$ \\
Late & & & & - & - \\
Pneumonitis & $22(63)$ & $4(11)$ & $6(17)$ & - & - \\
Esophageal narrowing/obstruction & - & $2(6)$ & - & - & - \\
Tracheal stenosis/obstruction & - & $2(6)$ & - & - & $2(3)$ \\
Pleural effusion & $5(14)$ & $4(11)$ & - & - & $2(6)$ \\
Hemoptysis & - & - & $7(20)$ & - & \\
All & $27(77)$ & $12(34)$ & & & - \\
\hline
\end{tabular}

CTCAE v 4.0, the Common Terminology Criteria for Adverse Events Version 4.0.
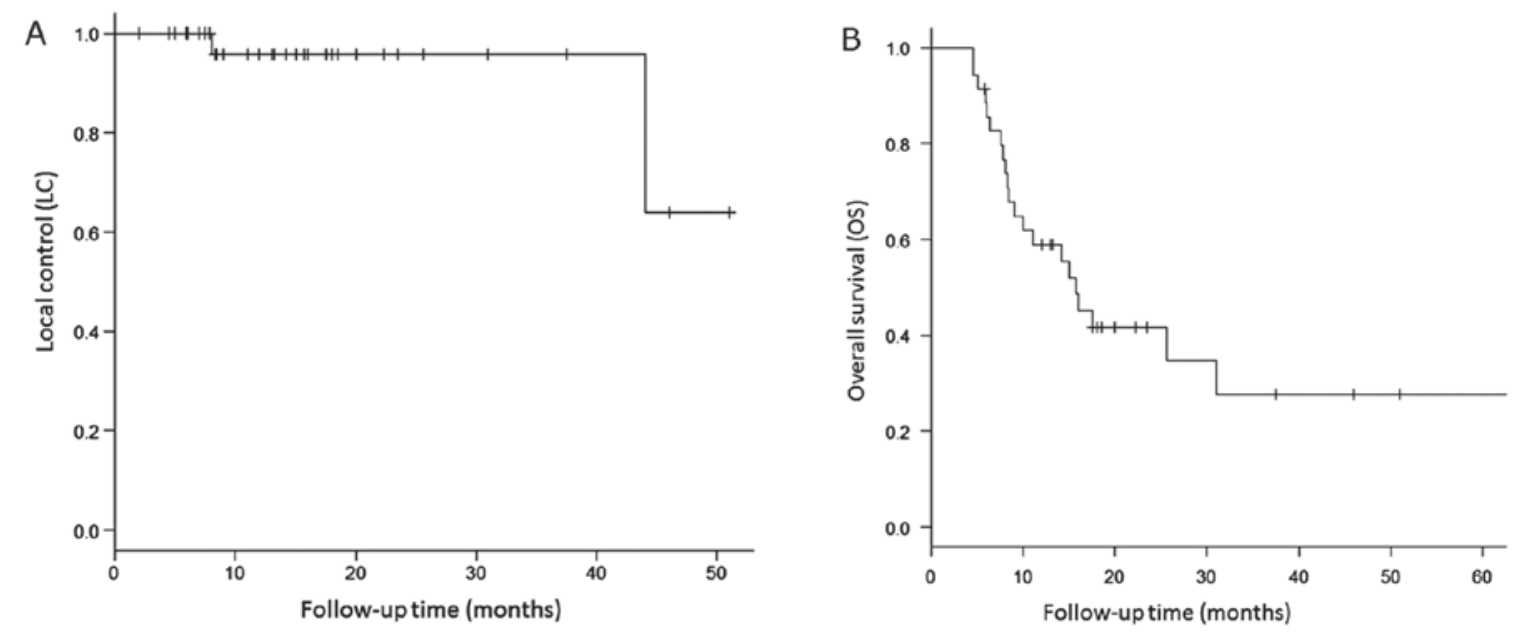

Figure 1. Kaplan-Meier curves of (A) local control rates (LCR) and (B) overall survival (OS) in the whole cohort.

cancer, with LR occurring 44 months after SBRT. The second was a postoperative case for a recurrent NSCLC. Local recurrence occurred 8 months after salvage SBRT and the patient died 2 months later. This was the only case of recurrence within 2 years, and for primary NSCLC cases received SBRT as the initial treatment, there has not been any LR at the present time. The 1-/2-year LCR were both 96\% (95\% CI: 74.8-99.4\%), and the median LCR has not been reached. The survival curves for LC are shown in Fig. 1A.

Twenty-two patients (62.9\%) died, of whom 10 died due to primary disease (including 4 NSCLC, and 6 non-NSCLC), 2 were treatment-related, and 10 were due to cause-specific death. Distant metastases occurred in 10 cases, 6 of which were the cases with pulmonary oligo-recurrences from non-NSCLC. Recurrence or death occurred in 24 patients $(68.6 \%)$. The 1- and 2-year OS of the whole cohort was $59.0 \%$ (95\% CI: 40.8-73.3\%) and 41.6\% (95\% CI: 24.5-58.0\%), respectively. The median OS was 15.7 months (range: 8.4-31 months). The 1- and 2-year OS of the primary NSCLC subgroup was
66.7\% (95\% CI: $37.5-84.6 \%$ ) and $50.0 \%$ (95\% CI: $22.2-72.6 \%$ ); that of the recurrent NSCLC subgroup was $50.0 \%$ (95\% CI: $20.9-73.6 \%$ ) and $30.0 \%$ (95\% CI: 7.7-56.9\%); and that of non-NSCLC subgroup (pulmonary oligo-metastases/recurrence of other cancers) was $60 \%$ (95\% CI: 19.6-85.2\%) and 45\% (95\% CI: $10.8-75.1 \%$ ), respectively. The 1- and 2-year RFS of the NSCLC subgroup was $51.9 \%$ (95\% CI: 31.9-68.5\%) and $38.9 \%$ (95\% CI: 20.5-57.0\%), respectively. Median RFS has not been reached. The survival curves for OS are shown in Fig. 1B.

AEs. Table III describes the AEs occurring in the patients. Nine patients experienced grade $\geq 3$ toxicity, representing $26 \%$ of the subjects. Two of these were grade 5, one pneumonitis and one hemoptysis.

Comparison of the patient characteristics of grade $\geq 3$ and $<3$ cases of pneumonitis is shown in Table IV. Although we tried to identify factors which showed significant differences in the two groups using the Chi-square 
Table IV. Comparison of the patient characteristics of grade $\geq 3$ and $<3$ cases of pneumonitis.

\begin{tabular}{|c|c|c|c|}
\hline \multirow[b]{2}{*}{ Characteristic } & \multicolumn{2}{|c|}{ Adverse events, no. (\%) } & \multirow[b]{2}{*}{ P-value (univariate) } \\
\hline & Grade $\geq 3$ & Grade $<3$ & \\
\hline Total $(n=35)$ & $\mathrm{n}=7$ & $\mathrm{n}=28$ & \\
\hline \multicolumn{4}{|l|}{ Age } \\
\hline$\geq 75$ & $3(42.9)$ & $14(50)$ & 0.99 \\
\hline \multicolumn{4}{|l|}{ Sex } \\
\hline Male & $6(85.7)$ & $19(67.9)$ & 0.64 \\
\hline \multicolumn{4}{|l|}{ KPS } \\
\hline$<90$ & $3(42.9)$ & $5(17.9)$ & 0.31 \\
\hline \multicolumn{4}{|l|}{ Surgical history } \\
\hline Yes & $4(57.1)$ & $14(50)$ & 0.99 \\
\hline \multicolumn{4}{|l|}{ COPD } \\
\hline Yes & $3(42.9)$ & $8(28.6)$ & 0.65 \\
\hline \multicolumn{4}{|l|}{ KL-6 } \\
\hline$>500$ & $1(14.3)$ & $1(3.6)$ & 0.36 \\
\hline \multicolumn{4}{|l|}{ Smoking history (Yes) } \\
\hline Yes & $6(85.7)$ & $17(60.7)$ & 0.38 \\
\hline Current & $3(42.9)$ & $6(21,4)$ & 0.34 \\
\hline \multicolumn{4}{|l|}{ Cancer type } \\
\hline Primary NSCLC & $5(62.5)$ & $7(25)$ & 0.03 \\
\hline Recurrent NSCLC & $2(28.6)$ & $12(42.9)$ & 0.68 \\
\hline Oligo-metastases & $0(0)$ & $8(28.6)$ & 0.17 \\
\hline \multicolumn{4}{|l|}{ Definition of 'Central' } \\
\hline RTOG 0236 definition & $4(57.1)$ & $15(53.6)$ & 0.99 \\
\hline \multicolumn{4}{|l|}{ Maximum diameter } \\
\hline$\geq 3 \mathrm{~cm}$ & $2(28.6)$ & $16(57.1)$ & 0.23 \\
\hline$\geq 4 \mathrm{~cm}$ & $2(28.6)$ & $7(25)$ & 0.99 \\
\hline \multicolumn{4}{|l|}{ PTV volume } \\
\hline$\geq 100 \mathrm{~cm}^{3}$ & $2(28.6)$ & $6(21.4)$ & 0.65 \\
\hline \multicolumn{4}{|l|}{ Lung V5 } \\
\hline$\geq 25 \%$ & $4(57.1)$ & $18(64.3)$ & 0.99 \\
\hline \multicolumn{4}{|l|}{ Lung V20 } \\
\hline$\geq 10 \%$ & $3(42.9)$ & $16(57.1)$ & 0.68 \\
\hline \multicolumn{4}{|l|}{ MLD } \\
\hline$\geq 500 \mathrm{cGy}$ & $5(62.5)$ & $21(75)$ & 0.99 \\
\hline
\end{tabular}

RTOG 0236 definition $(15,16)$. KPS, karnofsy performance scale; COPD, chronic obstructive pulmonary disease; KL-6, sialylated carbohydrate antigen Krebs von den Lungen-6; NSCLC, non-small cell lung cancer; RTOG 0236, radiation therapy oncology group trial 0236; PTV, planning treatment volume; V5 (20), percentage of the volume of an organ receiving 5 (20) Gy; MLD, mean lung dose. All P-values were calculated using Pearson's $\chi^{2}$ test.

test, we failed to show the risk factors associated with pneumonitis.

Here we described the details of these two AEs and esophagitis, which are the most common and can be severe. Pneumonitis and hemoptysis are late effects of irradiation, which occur after months to years after irradiation, and are often irreversible changes. It is thought that the immunological mechanism is involved, but the mechanism of development is not clear.
On the other hand, esophagitis is a type of mucositis caused by irradiation, and it develops and relieves in weeks after irradiation.

Pneumonitis. Pneumonitis in seven of nine cases was grade $\geq 3$, of which one was grade 5 . The time to onset of pneumonitis in these cases was 6 months (range, 2-7 months) after treatment. Table IV compares characteristics in subjects with grade $\geq 3$ vs. $<3$ pneumonitis. We could not identify risk 


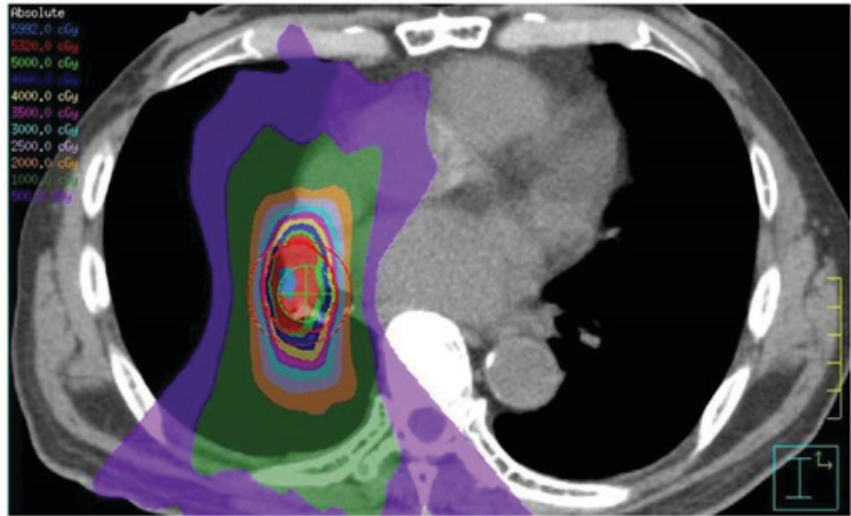

Figure 2. Irradiation field of a patient with grade 5 pneumonitis. He developed pneumonitis 5 months after irradiation, and received corticosteroid pulse therapy, but died on day 30 after onset.

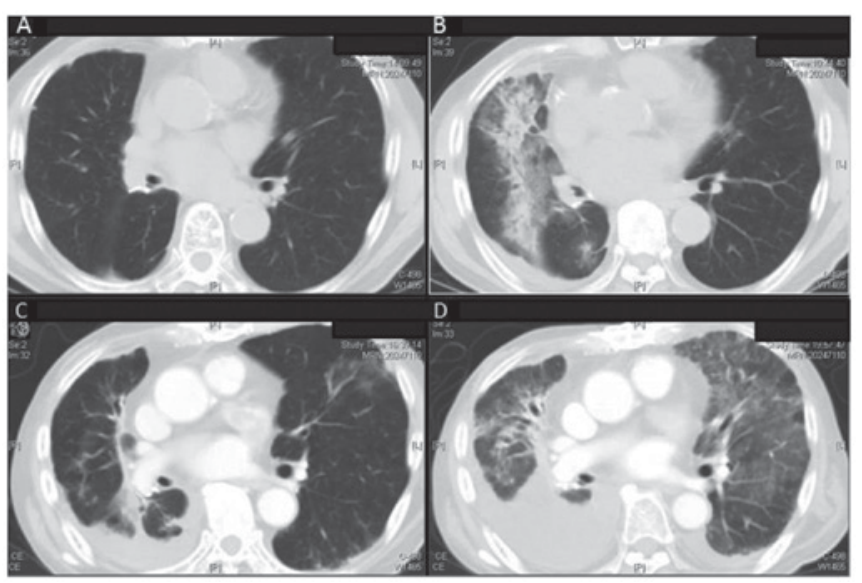

Figure 3. A series of images on the progress of pneumonitis in a patien with grade 5 pneumonitis; (A) before SBRT, (B) 2 months after treatment, (C) 7 months after treatment (at onset), (D) 8 months after treatment (5 days before death). SBRT, stereotactic body radiotherapy.

factors significantly associated with grade $>3$ pneumonitis. A case of grade 5 pneumonitis was seen in a 79-year-old man with a history of video-assisted thoracoscopic surgery (VATS) lobectomy for NSCLC in the right lower lobe. He developed an enlarged ipsilateral hilar lymph node $(26 \mathrm{~mm})$ 5 months after surgery, and received SBRT. He had stopped smoking 45 years before treatment, and was free from COPD or other lung chronic diseases. The pulmonary dose was as follows: V5 $=34.7 \%$, V20 $=9.7 \%, \mathrm{MLD}=6.44 \mathrm{~Gy}$. $\mathrm{He}$ developed pneumonitis 5 months after irradiation, and was hospitalized and received corticosteroid pulse therapy, but died on day 30 after onset. The image of irradiation field and a series of follow-up CT images of this patient are shown in Figs. 2 and 3.

Hemoptysis. One patient in our cohort died of hemoptysis, likely attributable to SBRT. The patient was a 64-year-old man with a history of VATS lobectomy for primary NSCLC (squamous cell carcinoma) pT2aNOM0 p-Stage IB. Two years later, single oligo-recurrence (right S6) appeared and SBRT was performed as a salvage treatment. Bloody sputum and slight fever appeared 9 months after treatment. Because

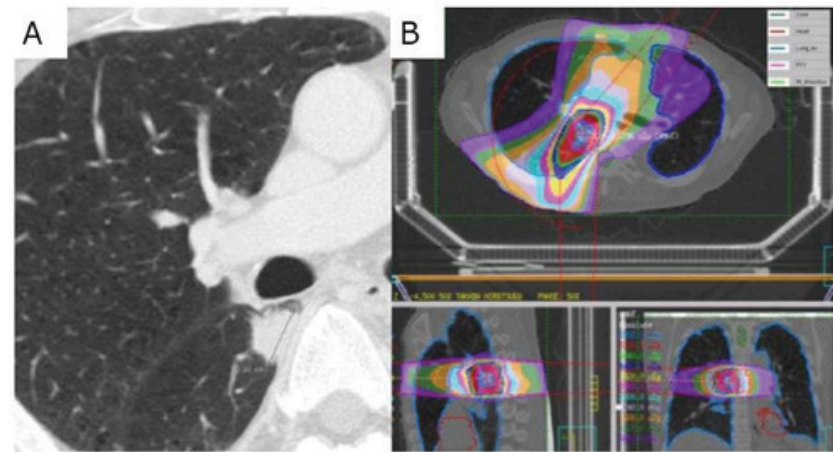

Figure 4. (A) A CT image before SBRT and (B) The irradiation field of a patient with grade 5 hemoptysis. He had massive hemoptysis ten months after SBRT and died. CT, computed tomography; SBRT, stereotactic body radiotherapy.

there was no deterioration of pneumonia or tumor recurrence in CT imaging, he was followed up without treatment. One month later, massive hemoptysis occurred and he died. The diameter of the target lesion was $20 \mathrm{~mm}$, the distance from the right main bronchus was $4 \mathrm{~mm}$, the maximum tracheal dose was 34.02 Gy (point), and the maximum bronchial dose was 63.33 Gy (point) (Fig. 4).

Esophagitis. In this group, no patient developed grade $\geq 3$ esophageal toxicity, including three patients $(8.6 \%)$ in whom the PTV overlapped the esophagus. Only one patient $(2.9 \%)$ developed grade 2 esophagitis. In this case, the tumor touched the esophagus, and the maximum esophageal dose at that point was $59.62 \mathrm{~Gy} / 7 \mathrm{fr}$. The mean maximum esophageal dose was 31.25 Gy for the point dose and $12.88 \mathrm{~Gy}$ for the $5 \mathrm{cc}$ dose $(17,24-26)$.

\section{Discussion}

SBRT provides excellent LC for peripheral lung tumors, with $>90-95 \%$ 2-year LCR $(5,16,23,27,28)$. In reports on SBRT of centrally located tumors, on the other hand, 2-year LCR ranges from 60 (29) to $94 \%$ (30). This is thought to be related to the lower $\mathrm{BED}_{10}$ used to avoid severe AEs.

The impact of BED on LC is widely known, and $\mathrm{BED}_{10}$ $\geq 100$ has been established as a significant predictor of $\mathrm{LC}$ (31). In reports with $\mathrm{BED}_{10}<100 \mathrm{~Gy}, \mathrm{LC}$ is relatively poor. Andratschke et al reported a 3-year LCR of 64\%, and OS of $29 \%$ (32). Oshiro et al reported a 2-year LCR of $60 \%$ with $\mathrm{BED}_{10}=80$ Gy (29), and Bradley et al reported an $86 \%$ 2-year LCR, and 75\% 2-year OS with $\mathrm{BED}_{10}=86 \mathrm{~Gy}$ (33). As for reports of $\geq 100 \mathrm{~Gy}$, Timmerman et al reported a 2-year LCR of 95\% using a regimen of 60-66 Gy in $3 \mathrm{fr}$ (13), and Rowe et al reported a 2 -year LCR of $94 \%$ with a $\mathrm{BED}_{10}$ $\geq 100 \mathrm{~Gy}$, and $80 \%$ when $\mathrm{BED}_{10}<100 \mathrm{~Gy},(\mathrm{P}=0.02)(34)$. Milano et al reported relatively poor results with the high dose: The 2-year LCR was $73 \%$ and the 2-year OS was $72 \%$ with $\mathrm{BED}_{10}=100 \mathrm{~Gy}$ (35). As they stated in their paper, the poorer OS and LC of their series likely reflected their patient population, which included stagel NSCLC, non-stage 1 NSCLC (NSCLC Stage 1:2:3=7:4:6), and oligo-recurrences. The 2-year survival of each group was 72, 12 and $49 \%$ respectively, suggesting very different patient populations. 
In our results, six of eight oligo-recurrences re-relapsed (75\%), while only four of 28 (14\%) NSCLC cases recurred, suggesting that the results are better in NSCLC.

In 2006, Timmerman et al reported treating 70 patients with $\mathrm{T} \leq 2$ NOM0 NSCLC using SBRT with 60-66 Gy in $3 \mathrm{fr}$, and Grade 3-5 toxicity occurred in a total of 14 patients (20\%), including six grade 5 cases (13). They stated that four of the six deaths from toxicity were in patients with central tumors, and that the risk of severe toxicity increased 11-fold in central lesions compared with peripheral ones (13). Thereafter, many researchers have published on the increased risk of SBRT for central lesions, and the central location is considered to be an independent risk factor $(36,37)$. Recently, several groups have reported their experience with central SBRT using a larger number of fractions ( $\geq 5 \mathrm{fr}$ ) and smaller doses per fraction, and suggested that their regimen would be safer and more appropriate. Haasbeek et al achieved a 3-year LCR of 90.2\% and 3-year OS of $51.1 \%$ with no grade 4/5 AEs administering $60 \mathrm{~Gy} / 8 \mathrm{fr}$, finding no significant differences between central and peripheral tumors (38). Chang et al (39) and Li et al (40) reported the results of their regimen using $70 \mathrm{~Gy} / 10 \mathrm{fr}$; the median OS was 55.6 months and the 3-year OS rate was $70.5 \%$, with only $1 \%$ grade $\geq 3$ pneumonitis and no grade 4 or 5 toxicity $(39,40)$.

On the other hand, in our study, all treated with $56 \mathrm{~Gy} / 7 \mathrm{fr}$, 9 of 35 cases (25.7\%) had grade $\geq 3$ AEs (of which 7 cases were pneumonia), This is somewhat higher than the above reports with equivalent dose prescriptions $(5,10,39,40)$. In attempt to clarify risk factors related to severe pneumonia, we examined the difference between cases with and without AEs of grade 3 or higher among our subjects. Although we were unable to identify factors which showed significant differences in the two groups (Table IV), Roesch et al have written an interesting report on this matter. They classified 'central tumors' by risk based on three criteria: tumor size, OAR infiltration, and distance from the carina (10). They argued that the most prominent contraindications for SBRT (so-called 'high-risk' cases) were proximity to the carina, possible infiltration of the central airways (tumor immediately adjacent to the main bronchus) and tumor size $>4 \mathrm{~cm}$. According to their questionnaire survey, SBRT for high-risk cases was rejected by almost all radiation oncologists. If this classification were applied to our 35 cases, 17 (48.6\%) would be classified as 'high-risk' as defined by Roesch et al Certainly, among our cases experiencing grade $\geq 3$ AEs, 5 cases $(55.6 \%)$ were classifiable as 'high-risk' (10).

In addition, half of our patients had a history of thoracic surgery. The treatment of tumors arising post-pneumonectomy is often difficult, as subsequent surgery is often not feasible due to the higher risk of re-operation and lower lung function $(41,42)$. Data on cure for patients who develop a second tumor after pneumonectomy are scarce, and historic outcomes with conventional radiotherapy have been poor with a narrow therapeutic ratio $(43,44)$. Diagnosis of tumor localization is often difficult in these cases. The use of luminescent probes could be helpful for it. The information about peer efforts for analysis of detection platforms in the introduction has been reported (45-50). We have actively treated post-surgery patients with oligo-recurrent/secondary cancers using SBRT, and achieved good LC.
Previous reports on the efficacy and safety of central SBRT mainly focused on early stage NSCLC (38-40). In clinical practice, in contrast, it is often necessary to perform radiation therapy for high-risk cases where other treatments are more difficult. In the present paper, we also reported on SBRT for high risk cases such as postoperative recurrence and large tumors. Such an examination appears to be useful for selection and expansion of the target of central SBRT.

Limitations of this study are the small number of cases and short observation period. Although this paper focused on AEs, it is not sufficient to discuss survival period, and further observation is necessary in the future. Retrospective observational studies will inevitably have missing data, such as loss of pathological diagnosis and laboratory findings.

We reported the result of SBRT for central lesions with $56 \mathrm{~Gy} / 7 \mathrm{fr}$. Considering the background of the subject, tumor control of our central SBRT is promising, especially in primary NSCLC. However, the safety of SBRT to central lung cancer is still controversial.

\section{Acknowledgements}

The authors would like to thank Mrs. Libby Cone for editing the draft of this manuscript.

\section{Funding}

This study was partially supported by a Grant-in-Aid from JSPS (Japan Society for the Promotion of Science) KAKENHI JP Scientific Research (C) grant number 15K08692.

\section{Availability of data and materials}

The datasets used and/or analyzed during the current study are available from the corresponding author on reasonable request.

\section{Authors' contributions}

SA collected and assembled the data, drafted the manuscript and critically revised the article for important intellectual content. HY and WT supervised all the above work, and conceived the study design. AH and TO interpreted the collected data. SO, KaN and TI contributed to acquisition and analysis of the data. OA and $\mathrm{KeN}$ analyzed the data and helped to draft the manuscript. All authors read and approved the final manuscript.

\section{Ethics approval and consent to participate}

This study was approved by the Research Ethics Committee, University of Tokyo Hospital.

\section{Patient consent for publication}

Patients provided written consent for data collection and analysis.

\section{Competing interests}

The authors declare that they have no competing interests. 


\section{References}

1. de Perrot M, Licker M, Reymond MA, Robert J and Spiliopoulos A: Influence of age on operative mortality and long-term survival after lung resection for bronchogenic carcinoma. Eur Respir J 14: 419-422, 1999.

2. Chang JY, Senan S, Paul MA, Mehran RJ, Louie AV, Balter P, Groen HJ, McRae SE, Widder J, Feng L, et al: Stereotactic ablative radiotherapy versus lobectomy for operable stage I non-small-cell lung cancer: A pooled analysis of two randomised trials. Lancet Oncol 16: 630-637, 2015.

3. Dahele M, Hatton M, Slotman B and Guckenberger M: Stereotactic body radiotherapy: A survey of contemporary practice in six selected European countries. Acta Oncol 54 1237-1241, 2015.

4. Daly ME, Perks JR and Chen AM: Patterns-of-care for thoracic stereotactic body radiotherapy among practicing radiation oncologists in the United States. J Thorac Oncol 8: 202-207, 2013.

5. Chang JY, Bezjak A and Mornex F; IASLC Advanced radiation technology committee: Stereotactic ablative radiotherapy for centrally located early stage non-small-cell lung cancer: What we have learned. J Thorac Oncol 10: 577-585, 2015.

6. Tree AC, Khoo VS, Eeles RA, Ahmed M, Dearnaley DP, Hawkins MA, Huddart RA, Nutting CM, Ostler PJ and van As NJ: Stereotactic body radiotherapy for oligometastases. Lancet Oncol 14: e28-e37,2013.

7. Palma DA, Salama JK, Lo SS, Senan S, Treasure T, Govindan R and Weichselbaum R: The oligometastatic state - separating truth from wishful thinking. Nat Rev Clin Oncol 11: 549-557, 2014.

8. Niibe Y and Hayakawa K: Oligometastases and oligo-recurrence: The new era of cancer therapy. Jpn J Clin Oncol 40: 107-111, 2010.

9. Niibe Y and Chang JY: Novel insights of oligometastases and oligo-recurrence and review of the literature. Pulm Med 2012: 261096, 2012.

10. Roesch J, Panje C, Sterzing F, Mantel F, Nestle U, Andratschke N and Guckenberger M: SBRT for centrally localized NSCLCWhat is too central? Radiat Oncol 11: 157, 2016.

11. Siegenthaler MP, Pisters KM, Merriman KW, Roth JA, Swisher SG, Walsh GL, Vaporciyan AA, Smythe WR and Putnam JB Jr: Preoperative chemotherapy for lung cancer does not increase surgical morbidity. Ann Thorac Surg 71: 1105-1112, 2001.

12. Saito M, Furukawa K, Miura T and Kato H: Evaluation of T factor, surgical method, and prognostic factors in central type lung cancer. Jpn J Thorac Cardiovasc Surg 50: 413-417, 2002.

13. Timmerman R, McGarry R, Yiannoutsos C, Papiez L, Tudor K, DeLuca J, Ewing M, Abdulrahman R, DesRosiers C, Williams M and Fletcher J: Excessive toxicity when treating central tumors in a phase II study of stereotactic body radiation therapy for medically inoperable early-stage lung cancer. J Clin Oncol 24: 4833-4839, 2006.

14. Chaudhuri AA, Tang C, Binkley MS, Jin M, Wynne JF, von Eyben R, Hara WY, Trakul N, Loo BW Jr and Diehn M: Stereotactic ablative radiotherapy (SABR) for treatment of central and ultra-central lung tumors. Lung Cancer 89: 50-56, 2015.

15. Stanic S, Paulus R, Timmerman RD, Michalski JM, Barriger RB, Bezjak A, Videtic GM and Bradley J: No clinically significant changes in pulmonary function following stereotactic body radiation therapy for early- stage peripheral non-small cell lung cancer: An analysis of RTOG 0236. Int J Radiat Oncol Biol Phys 88: 1092-1099, 2014.

16. Timmerman R, Paulus R, Galvin J, Michalski J, Straube W, Bradley J, Fakiris A, Bezjak A, Videtic G, Johnstone D, et al: Stereotactic body radiation therapy for inoperable early stage lung cancer. JAMA 303: 1070-1076, 2010.

17. Modh A, Rimner A, Williams E, Foster A, Shah M, Shi W, Zhang Z, Gelblum DY, Rosenzweig KE, Yorke ED, et al: Local control and toxicity in a large cohort of central lung tumors treated with stereotactic body radiotherapy. Int J Radiat Oncol Biol Phys 90: 1168-1176, 2014.

18. Wheldon TE, Deehan C, Wheldon EG and Barrett A: The linear-quadratic transformation of dose-volume histograms in fractionated radiotherapy. Radiother Oncol 46: 285-295, 1998.

19. Yamashita H, Takahashi W, Haga A, Kida S, Saotome N and Nakagawa K: Stereotactic body radiotherapy for small lung tumors in the university of Tokyo hospital. Biomed Res Int 2014: $136513,2014$.
20. Nakagawa K, Haga A,Sakumi A, Yamashita H, Igaki H, Shiraki T, Ohtomo K, Iwai Y and Yoda K: Impact of flattening-filter-free techniques on delivery time for lung stereotactic volumetric modulated arc therapy and image quality of concurrent kilovoltage cone-beam computed tomography: A preliminary phantom study. J Radiat Res 55: 200-202, 2014.

21. Yamashita H, Takahashi W, Haga A and Nakagawa K: Radiation pneumonitis after stereotactic radiation therapy for lung cancer. World J Radiol 6: 708-715, 2014

22. Nakagawa K, Haga A, Kida S, Masutani Y, Yamashita H, Takahashi W, Sakumi A, Saotome N, Shiraki T, Ohtomo K, et al: 4D registration and 4D verification of lung tumor position for stereotactic volumetric modulated arc therapy using respiratory-correlated cone-beam CT. J Radiat Res 54: 152-156, 2013

23. Lagerwaard FJ, Haasbeek CJ, Smit EF, Slotman BJ and Senan S: Outcomes of risk-adapted fractionated stereotactic radiotherapy for stage I non-small-cell lung cancer. Int J Radiat Oncol Biol Phys 70: 685-692, 2008

24. Thomas TO, Hasan S, Small W Jr, Herman JM, Lock M, Kim EY, Mayr NA, Teh BS and Lo SS: The tolerance of gastrointestinal organs to stereotactic body radiation therapy: What do we know so far? J Gastrointest Oncol 5: 236-246, 2014.

25. Stephans KL, Djemil T, Diaconu C, Reddy CA, Xia P, Woody NM, Greskovich J, Makkar V and Videtic GM: Esophageal dose tolerance to hypofractionated stereotactic body radiation therapy: Risk factors for late toxicity. Int J Radiat Oncol Biol Phys 90: 197-202, 2014.

26. Pham AH, Yorke E, Rimner A and Wu AJ: Potential for interfraction motion to increase esophageal toxicity in lung SBRT. Technol Cancer Res Treat: 1533034617711353, 2017.

27. Chang JY, Liu H, Balter P, Komaki R, LiaoZ, Welsh J, Mehran RJ, Roth JA and Swisher SG: Clinical outcome and predictors of survival and pneumonitis after stereotactic ablative radiotherapy for stage I non-small cell lung cancer. Radiat Oncol 7: 152, 2012.

28. Taremi M, Hope A, Dahele M, Pearson S, Fung S, Purdie T, Brade A, Cho J, Sun A, Bissonnette JP and Bezjak A: Stereotactic body radiotherapy for medically inoperable lung cancer: Prospective, single-center study of 108 consecutive patients. Int J Radiat Oncol Biol Phys 82: 967-973, 2012.

29. Oshiro Y, Aruga T, Tsuboi K, Marino K, Hara R, Sanayama Y and Itami J: Stereotactic body radiotherapy for lung tumors at the pulmonary hilum. Strahlenther Onkol 186: 274-279, 2010.

30. Bral S, Gevaert T, Linthout N, Versmessen H, Collen C, Engels B, Verdries D, Everaert H, Christian N, De Ridder M and Storme G: Prospective, risk-adapted strategy of stereotactic body radiotherapy for early-stage non-small-cell lung cancer: Results of a Phase II trial. Int J Radiat Oncol Biol Phys 80: 1343-1349, 2011.

31. Onishi H, Araki T, Shirato H, Nagata Y, Hiraoka M, Gomi K, Yamashita T, Niibe Y, Karasawa K, Hayakawa K, et al: Stereotactic hypofractionated high-dose irradiation for stage I nonsmall cell lung carcinoma: Clinical outcomes in 245 subjects in a Japanese multiinstitutional study. Cancer 101: 1623-1631, 2004.

32. Andratschke N, Zimmermann F, Boehm E, Schill S, Schoenknecht C, Thamm R, Molls M, Nieder C and Geinitz H: Stereotactic radiotherapy of histologically proven inoperable stage I non-small cell lung cancer: Patterns of failure. Radiother Oncol 101: 245-249, 2011.

33. Bradley JD, El Naqa I, Drzymala RE, Trovo M, Jones G and Denning MD: Stereotactic body radiation therapy for early-stage non-small-cell lung cancer: The pattern of failure is distant. Int J Radiat Oncol Biol Phys 77: 1146-1150, 2010.

34. Rowe BP, Boffa DJ, Wilson LD, Kim AW, Detterbeck FC and Decker RH: Stereotactic body radiotherapy for central lung tumors. J Thorac Oncol 7: 1394-1399, 2012.

35. Milano MT, Chen Y, Katz AW, Philip A, Schell MC and Okunieff P: Central thoracic lesions treated with hypofractionated stereotactic body radiotherapy. Radiother Oncol 91: 301-306, 2009.

36. Oskan F: The quality of toxicity reporting and the story of the lung SBRT 'NO-FLY ZONe'. Int J Radiat Oncol Biol Phys 92: 514-515, 2015.

37. Timmerman RD: The quality of toxicity reporting and the story of the lung SBRT 'No-Fly Zone'. In Regard to Oskan. Int J Radiat Oncol Biol Phys 93: 726-727, 2015.

38. Haasbeek CJ, Lagerwaard FJ, Slotman BJ and Senan S: Outcomes of stereotactic ablative radiotherapy for centrally located early-stage lung cancer. J Thorac Oncol 6: 2036-2043, 2011. 
39. Chang JY, Li QQ, Xu QY, Allen PK, Rebueno N, Gomez DR, Balter P, Komaki R, Mehran R, Swisher SG and Roth JA: Stereotactic ablative radiation therapy for centrally located early stage or isolated parenchymal recurrences of non-small cell lung cancer: How to fly in a 'no fly zone'. Int J Radiat Oncol Biol Phys 88: 1120-1128, 2014.

40. Li Q, Swanick CW, Allen PK, Gomez DR, Welsh JW, Liao Z, Balter PA and Chang JY: Stereotactic ablative radiotherapy (SABR) using 70 Gy in 10 fractions for non-small cell lung cancer: Exploration of clinical indications. Radiother Oncol 112: 256-261, 2014.

41. Senthi S, Haasbeek CJ, Lagerwaard FJ, Verbakel WF, de Haan PF, Slotman BJ and Senan S: Radiotherapy for a second primary lung cancer arising post-pneumonectomy: Planning considerations and clinical outcomes. J Thorac Dis 5: 116-122, 2013.

42. Donington JS, Miller DL, Rowland CC, Deschamps C, Allen MS, Trastek VF and Pairolero PC: Subsequent pulmonary resection for bronchogenic carcinoma after pneumonectomy. Ann Thorac Surg 74: 154-159, 2002.

43. Rowell NP and Williams CJ: Radical radiotherapy for stage I/II non-small cell lung cancer in patients not sufficiently fit for or declining surgery (medically inoperable): A systematic review. Thorax 56: 628-638, 2001.

44. Lagerwaard FJ, Voet PW, van Meerbeeck JP, Burgers SA and Senan S; Rotterdam oncological thoracic study group: Curative radiotherapy for a second primary lung cancer arising after pneumonectomy-techniques and results. Radiother Oncol 62 : $21-25,2002$.
45. Zhou J, Amrane S, Korkut DN, Bourdoncle A, He HZ, Ma DL and Mergny JL: Combination of i-motif and G-quadruplex structures within the same strand: Formation and application. Angew Chem Int Ed Engl 52: 7742-7746, 2013.

46. Salmon H, Franciszkiewicz K, Damotte D, Dieu-Nosjean MC, Validire P, Trautmann A, Mami-Chouaib F and Donnadieu E: Matrix architecture defines the preferential localization and migration of T cells into the stroma of human lung tumors. J Clin Invest 122: 899-910, 2012.

47. He HZ, Chan DS, Leung CH and Ma DL: G-quadruplexes for luminescent sensing and logic gates. Nucleic Acids Res 41: 4345-4359, 2013.

48. Ma DL, He HZ, Leung KH, Chan DS and Leung CH: Bioactive luminescent transition-metal complexes for biomedical applications. Angew Chem Int Ed Engl 52: 7666-7682, 2013.

49. Carretero J, Shimamura T, Rikova K, Jackson AL, Wilkerson MD, Borgman CL, Buttarazzi MS, Sanofsky BA, McNamara KL, Brandstetter KA, et al: Integrative genomic and proteomic analyses identify targets for Lkb1-deficient metastatic lung tumors. Cancer Cell 17: 547-559, 2010.

50. Leung $\mathrm{CH}$, Zhong HJ, Yang $\mathrm{H}$, Cheng Z, Chan DS, Ma VP, Abagyan R, Wong CY and Ma DL: A metal-based inhibitor of tumor necrosis factor- $\alpha$. Angew Chem Int Ed Engl 51: 9010-9015, 2012.

This work is licensed under a Creative Commons Attribution-NonCommercial-NoDerivatives 4.0 International (CC BY-NC-ND 4.0) License. 